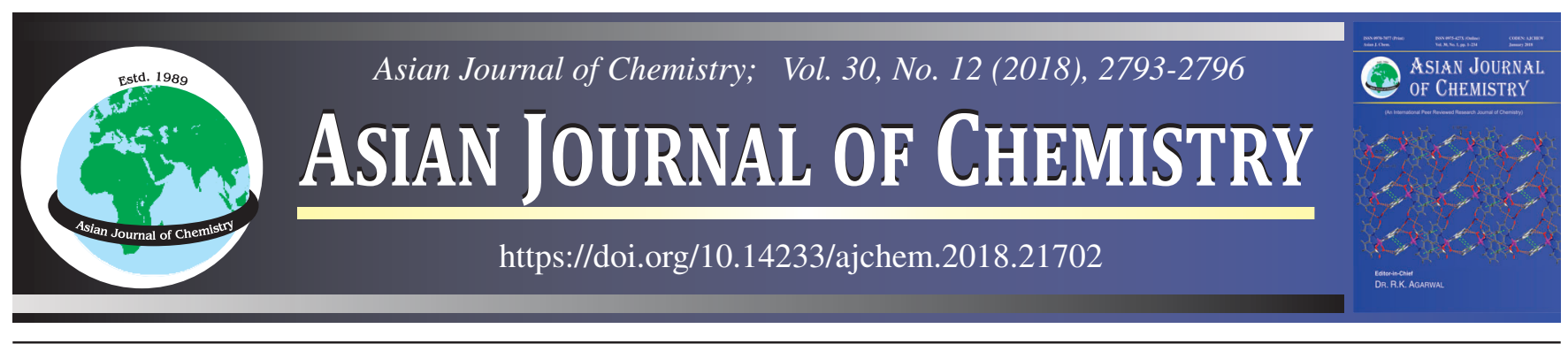

\title{
Micro-Determination and Assessment of Selected Heavy Metal Ions in Foundation Creams Commonly Used in Kingdom of Saudi Arabia using ICP-OES
}

\section{Maha Abdallah Alnuwaiser}

Department of Chemistry, Faculty of Science, Princess Nourahbint Abdulrahman University, P.O. Box 28445, Riyadh 11437, Saudi Arabia

Corresponding author: E-mail: maalnoussier@pnu.edu.sa

Received: 11 September 2018;

Accepted: 3 October 2018;

Published online: 31 October 2018;

AJC-19150

\begin{abstract}
Twenty-five different foundation cream brands were analyzed to detect the presence of heavy metals. These brands were manufactured in several different countries (China, Japan, USA, France, and USA) and locally available in Riyadh. The foundation creams varied in color intensity and tone (light to dark). These creams were pre-treated by microwave assisted acid-digestion prior to using inductively coupled plasma-optical emission spectroscopy to determine the presence of arsenic, mercury, lead and cadmium. The concentrations of these metals varied the levels of cadmium, arsenic and mercury were within permissible limits. However, lead concentrations far exceeded international limits, with creams from China showing elevated lead concentrations (upto $132.00 \mathrm{ppm}$ ). The concentration ranges for these metals were: $0.09-132.00 \mathrm{ppm}$ for $\mathrm{Pb}, 0.01-0.33$ for $\mathrm{Cd}, 0.04-0.66$ for As, and 0.01-0.74 for $\mathrm{Hg}$. A one-way variance analysis was performed for the different foundation cream brands with no significant differences observed within and between the groups.
\end{abstract}

Keywords: Heavy metals, Toxic effects, Cosmetics, Foundation creams.

\section{INTRODUCTION}

Heavy metals are ubiquitous in distribution and are natural components of the earth's crust. However, the increasing concentration of toxic heavy metals in the environment due to multifarious human activities is of primary concern [1]. Heavy metals, which are introduced in cosmetic products either to increase the value of the product, or are present as impurities or introduced illegally, pose risks to human health [2]. Though the use of heavy metals in cosmetics is prohibited, trace amounts are permitted, as per cosmetic product group standards. Most of the heavy metals are added either as color additives to provide fragrance or as preservatives, to increase the shelf-life of the products. Among the various cosmetics, foundation creams have been used increasingly in recent years for beautification or as skin protection agents against environmental stressors $[3,4]$. Foundations creams may contain $\mathrm{As}, \mathrm{Cd}, \mathrm{Pb}, \mathrm{Hg}$ and other hazardous heavy metals and the prolonged use of these harmful cosmetic products may lead to the accumulation of heavy metals in the body beyond the prescribed limits, thereby posing a risk to human health [5].
Apart from profiting financially, it is the responsibility of manufacturers to provide quality products that comply with international norms and standards, focusing on the safety of users. Several international agencies including the European Union [6] have prohibited the use of several heavy metals including $\mathrm{As}, \mathrm{Cd}, \mathrm{Pb}$ and $\mathrm{Hg}$ in cosmetic products owing to their toxic effects [7]. Toxic heavy metals like lead and cadmium are common contaminants in cosmetic products including foundation creams [8,9]. These metals produce harmful effects, some at low concentration, while others at high concentration, depending on the quantity and duration of use [10]. Cadmium is among the major heavy metals found in some natural colours and inorganic pigments in cosmetic products. Cadmium toxicity causes kidney damage and bone degradation even at low concentration. Lead affects the nervous system, leading to mental retardation and learning disability. Cadmium and lead accumulate in the human tissues, as they do not get metabolized by the body for absorption and utilization. Recent studies [9] have proved that lead causes intrauterine fatal death, nervous disorders, premature delivery, low birth weight and other behavioural abnormalities .

This is an open access journal, and articles are distributed under the terms of the Creative Commons Attribution-Non Commercial 4.0 International (CC BY-NC 4.0) License, which allows others to copy and redistribute the material in any medium or format, remix, transform, and build upon the material, as long as appropriate credit is given and the new creations are licensed under the identical terms. 
With increasing use of cosmetic products, their manufacturing, import, and marketing have also increased in Saudi Arabia [11]. Despite the presence of hazardous ingredients in foundation creams, awareness regarding their harmful effects is lacking in Saudi Arabia. Therefore, the objective of the present study is to estimate and verify the concentration of hazardous heavy metals namely, $\mathrm{As}, \mathrm{Hg}, \mathrm{Pb}$ and $\mathrm{Cd}$ in foundation creams marketed by different international brands in Saudi Arabia, with a focus on minimizing human health hazards.

\section{EXPERIMENTAL}

High-purity deionized water (Millipore) was used for dilution of the samples and standards. $\mathrm{HNO}_{3} 69 \%$, $\mathrm{HF} 50 \%$ and $\mathrm{H}_{2} \mathrm{O}_{2}$ $30 \%$ (Sigma-Aldrich) were used for the digestions.

Sampling: A total of 115 different samples $(n=115)$ of foundation creams were purchased randomly from Riyadh market, Saudi Arabia to analyze their heavy metal contents. These samples belonged to 25 different brands and were further categorized into five groups based on the country of origin.

Sample digestion: First $0.15 \mathrm{~g}$ of each sample was added to PTFE vessels. A mixture of $6 \mathrm{~mL} \mathrm{HNO}_{3}$ and $2 \mathrm{~mL} \mathrm{H}_{2} \mathrm{O}_{2}$ was added to each vessel, following which microwave digestion was performed sequentially for $10 \mathrm{~min}$ at $400 \mathrm{~W}, 5 \mathrm{~min}$ at $500 \mathrm{~W}$, $5 \mathrm{~min}$ at $600 \mathrm{~W}$ and $10 \mathrm{~min}$ at $400 \mathrm{~W}$. The digestion was followed by cooling at room temperature for $15 \mathrm{~min}$ till the completion of the reaction. The samples were passed through Whatman filter paper No. 1 and diluted to $20 \mathrm{~mL}$ with high-purity deionized water in a $50 \mathrm{~mL}$ volumetric flask. They were then digested in triplicates along with reagent blanks. Standard references of six concentration levels were used.

Sample analysis: The digested samples were analyzed to determine arsenic, cadmium, lead and mercury concentration by inductively coupled plasma-optical emission spectroscopy (ICP-OES, Perkin Elmer 6100), as per standard measurement parameters (Table-1).

\begin{tabular}{ll}
\multicolumn{1}{c}{ TABLE-1 } \\
& $\begin{array}{l}\text { INSTRUMENTAL PARAMETERS OF } \\
\text { ICP-OES, PERKIN ELMER 2100 }\end{array}$ \\
\hline & ICP-OES \\
\hline Radio frequency & $1400 \mathrm{~W}$ \\
Plasma flow & $15.0 \mathrm{~L} / \mathrm{min}$ \\
Auxiliary flow & $0.60 \mathrm{~L} / \mathrm{min}$ \\
Sample gas flow & $0.013 \mathrm{~L} / \mathrm{min}$ \\
\hline
\end{tabular}

Statistical analysis: The data obtained were subjected to statistical analysis using SPSS (ver.25) to calculate the mean and standard deviation (SD). To compare the mean concentrations of the metals between different groups of brands, one way analysis of variance (ANOVA) was used.

\section{RESULTS AND DISCUSSION}

The mean concentration of lead across different brands varied from $0.09 \pm 0.07 \mathrm{ppm}$ to $132.00 \pm 141.56 \mathrm{ppm}$, that of cadmium varied from $0.01 \pm 0.04 \mathrm{ppm}$ to $0.33 \pm 0.19 \mathrm{ppm}$, that of arsenic varied from $0.04 \pm 0.01 \mathrm{ppm}$ to $0.66 \pm 0.01 \mathrm{ppm}$ and that of mercury varied from $0.01 \pm 0.11$ to $0.74 \pm 0.14 \mathrm{ppm}$ (Table-2). The concentrations that were below the detection limits are represented as not detected (Table-2). Among the different heavy metals analyzed, the concentration of lead (132 ppm) exceeded the maximum permissible limit (10 ppm) in some cosmetic brands $[10,12]$. The adverse health effects of lead are well-established $[9,13]$. Lead can easily cross the placenta and damage the fetal brain; moreover, it can cause temporary to permanent damage of the nervous system, kidney,

TABLE-2

HEAVY METAL CONCENTRATIONS (ppm) IN DIFFERENT BRANDS OF FOUNDATION CREAM FROM FIVE DIFFERENT COUNTRIES (VALUES ARE IN MEAN \pm STANDARD DEVIATION)

\begin{tabular}{|c|c|c|c|c|c|c|}
\hline Brands & Country of origin & Sample size (n) & $\mathrm{Pb}$ & $\mathrm{Cd}$ & As & $\mathrm{Hg}$ \\
\hline 1 & China & 6 & $0.79 \pm 1.34$ & $0.04 \pm 1.36$ & $0.53 \pm 0.09$ & $0.03 \pm 0.01$ \\
\hline 2 & China & 4 & $0.35 \pm 0.38$ & $0.04 \pm 0.41$ & $0.66 \pm 0.01$ & $0.03 \pm 1.84$ \\
\hline 3 & China & 4 & $0.98 \pm 0.55$ & $0.07 \pm 9.28$ & $0.33 \pm 0.08$ & $0.01 \pm 1.36$ \\
\hline 4 & China & 4 & $0.77 \pm 3.30$ & $0.05 \pm 2.37$ & $0.15 \pm 0.02$ & $0.01 \pm 0.23$ \\
\hline 5 & China & 8 & $1.63 \pm 1.21$ & $0.10 \pm 1.34$ & Not detected & $0.02 \pm 0.25$ \\
\hline 6 & China & 6 & $0.91 \pm 1.02$ & $0.05 \pm 0.10$ & Not detected & $0.02 \pm 0.02$ \\
\hline 7 & China & 6 & $132.00 \pm 1.56$ & $0.09 \pm 1.07$ & Not detected & $0.04 \pm 0.16$ \\
\hline 8 & China & 6 & $0.92 \pm 0.38$ & $0.07 \pm 0.01$ & $0.04 \pm 0.07$ & $0.02 \pm 0.18$ \\
\hline 9 & China & 6 & $1.40 \pm 0.08$ & $0.06 \pm 0.04$ & Not detected & $0.01 \pm 0.11$ \\
\hline 10 & Japan & 3 & $4.58 \pm 2.90$ & $0.01 \pm 0.11$ & $0.04 \pm 0.05$ & $0.02 \pm 0.45$ \\
\hline 11 & Japan & 3 & $2.37 \pm 2.43$ & $0.02 \pm 0.01$ & $0.05 \pm 0.06$ & $0.03 \pm 0.35$ \\
\hline 12 & Japan & 3 & $0.10 \pm 0.33$ & $0.06 \pm 0.03$ & Not detected & Not detected \\
\hline 13 & Japan & 3 & $9.62 \pm 0.09$ & Not detected & $0.06 \pm 0.03$ & Not detected \\
\hline 14 & Japan & 4 & $4.06 \pm 1.72$ & $0.01 \pm 0.03$ & $0.18 \pm 2.40$ & $0.74 \pm 0.14$ \\
\hline 15 & Japan & 3 & $0.72 \pm 2.22$ & $0.01 \pm 0.01$ & $0.47 \pm 1.44$ & $0.02 \pm 2.73$ \\
\hline 16 & Italy & 4 & $0.31 \pm 0.14$ & $0.01 \pm 0.02$ & Not detected & Not detected \\
\hline 17 & Italy & 8 & $1.14 \pm 0.04$ & $0.07 \pm 0.03$ & $0.03 \pm 2.60$ & $0.05 \pm 0.11$ \\
\hline 18 & Italy & 6 & $0,89 \pm 0.06$ & $0.09 \pm 0.07$ & $0.04 \pm 0.11$ & Not detected \\
\hline 19 & Italy & 3 & $2.87 \pm 0.10$ & $0.06 \pm 0.08$ & $0.16 \pm 0.01$ & Not detected \\
\hline 20 & Italy & 3 & $2.66 \pm 0.22$ & $0.03 \pm 0.01$ & $0.04 \pm 0.03$ & Not detected \\
\hline 21 & France & 4 & $0.12 \pm 0.01$ & $0.01 \pm 0.02$ & Not detected & Not detected \\
\hline 22 & France & 3 & $0.09 \pm 0.07$ & $0.33 \pm 0.19$ & $0.08 \pm 0.07$ & $0.04 \pm 0.10$ \\
\hline 23 & France & 3 & $3.09 \pm 0.23$ & $0.05 \pm 0.11$ & $0.04 \pm 0.01$ & Not detected \\
\hline 24 & USA & 6 & $1.02 \pm 0.25$ & $0.01 \pm 0.04$ & Not detected & Not detected \\
\hline 25 & USA & 6 & Not detected & $0.10 \pm 0.09$ & $0.10 \pm 0.11$ & Not detected \\
\hline
\end{tabular}


and liver [14].The concentration of other heavy metals like $\mathrm{Cd}$, As and $\mathrm{Hg}$ were estimated to be within the permissible limit $(<3$ ppm) [12]. However, prolonged use of cadmium may cause bioaccumulation, leading to kidney dysfunction. Further, $\mathrm{Pb}, \mathrm{Cd}$ and As can easily cross the skin barrier and may become systemically available with concomitant use of heavy-metal-containing cosmetics $[15,16]$. The range of concentrations of $\mathrm{Pb}, \mathrm{Cd}$, As and $\mathrm{Hg}$ detected here is less than in most of the previous studies $[9,13,15,17]$.

The concentrations of heavy metals in the cosmetic brands, classified on the basis of country of origin are shown in Fig. 1. A high mean concentration of lead was detected from brands of Chinese origin (198.01 ppm), followed by those from Japan (41.47 ppm), Italy (18.98 ppm), France (11.00 ppm) and USA $(5.10 \mathrm{ppm})$. The highest mean concentrations of mercury were found in brands of Japanese (1.35 ppm) and Chinese ( $0.21 \mathrm{ppm})$ origin, followed by those from France $(0.13 \mathrm{ppm})$ and Italy $(0.10$ $\mathrm{ppm})$. No traces of mercury were detected in any of the samples from the USA. The high lead concentrations may also be due to impurities generated during production $[16,18]$. The highest arsenic concentration was detected in brands of Chinese (1.90) and Japanese (1.33) origin, followed by those from Italy ( 0.54$)$, USA (0.50) and France (0.40). With regard to cadmium, brands of French origin showed a high mean concentration (1.30), followed by those from China (0.63), USA (0.55), Italy (0.52), and Japan (0.18). Like other heavy metals, the neurotoxic effects of cadmium are well-established [19]. Moreover, the prolonged use of heavy-metal-containing cosmetics may interfere with the functions of nutritionally essential metals, thereby aggravating the toxic effects [5].

Results for the one-way ANOVA revealed no significant differences in the heavy metal concentrations among the different brands of foundation cream, within and between the groups (Table-3). Owing to the wide availability of Chinese

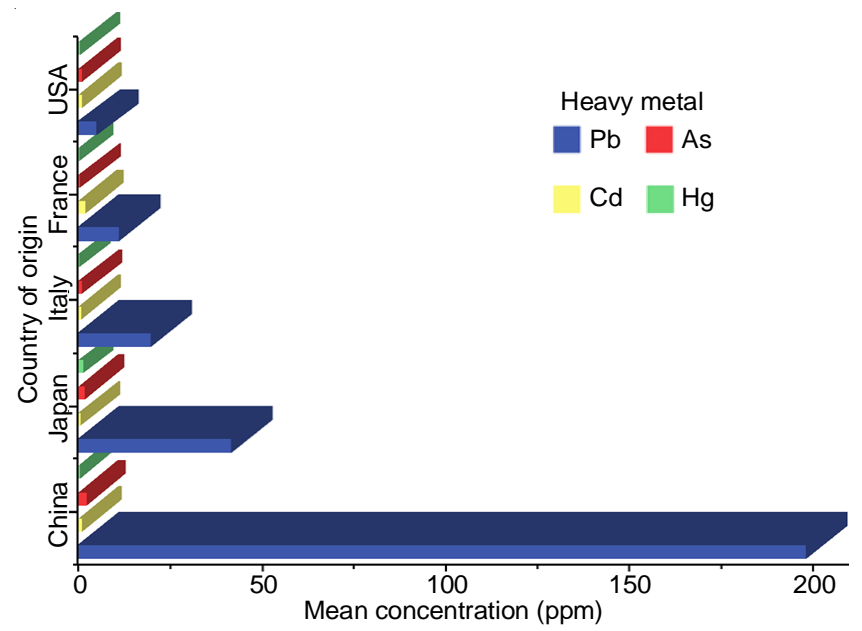

Fig. 1. Variations in heavy metal concentrations in foundation creams marketed by different countries

products in Saudi markets, nine different brands of foundation cream were separately analyzed for safety assessment. As stated above, most Chinese-origin brands showed higher metal concentrations, especially for $\mathrm{Pb}$ (132ppm) and $\mathrm{As}$ (0.66ppm), compared with brands from other countries (Table-4). However, the concentration of $\mathrm{Hg}(0.21 \mathrm{ppm})$ was within the permissible limit. This corroborates with earlier findings of mercury level in Chinese cosmetic brands [20]. These high concentrations may be attributed to poor safety and regulatory measures adopted during the manufacturing process. It is evident from the present study, that cosmetic brands from most countries outside the European Union contain heavy metal concentrations in excess of the safe limit [1]. Though metals like lead and cadmium are not in use in most European Union countries, traces of these metals were detected as impurities, which may be due to follow-up processes post manufacture [18]. There is a wide variation in

\begin{tabular}{|c|c|c|c|c|c|c|}
\hline \multicolumn{7}{|c|}{$\begin{array}{c}\text { TABLE-3 } \\
\text { ONE-WAY ANALYSIS OF VARIANCE (ANOVA) FOR HEAVY METAL } \\
\text { CONCENTRATIONS AMONG DIFFERENT BRANDS OF FOUNDATION CREAM }\end{array}$} \\
\hline Heavy metal & & Sum of squares & df & Mean square & $\mathrm{F}$ & Significance \\
\hline \multirow[t]{3}{*}{$\mathrm{Pb}$} & Between groups & 1021.705 & 4.0 & 255.426 & 0.333 & 0.852 \\
\hline & Within groups & 15323.726 & 20.0 & 766.186 & & \\
\hline & Total & 16345.431 & 24.0 & & & \\
\hline \multirow[t]{3}{*}{$\mathrm{Cd}$} & Between groups & 0.025 & 4 & 0.006 & 1.700 & 0.189 \\
\hline & Within groups & 0.075 & 20 & 0.004 & & \\
\hline & Total & 0.100 & 24 & & & \\
\hline \multirow[t]{3}{*}{ As } & Between groups & 0.096 & 4 & 0.024 & 0.683 & 0.612 \\
\hline & Within groups & 0.702 & 20 & 0.035 & & \\
\hline & Total & 0.798 & 24 & & & \\
\hline \multirow[t]{3}{*}{$\mathrm{Hg}$} & Between groups & 0.067 & 4 & 0.017 & 0.753 & 0.568 \\
\hline & Within groups & 0.444 & 20 & 0.022 & & \\
\hline & Total & 0.511 & 24 & & & \\
\hline
\end{tabular}

\begin{tabular}{|c|c|c|c|c|c|c|c|c|c|}
\hline \multirow{3}{*}{ Elements } & \multicolumn{8}{|c|}{$\begin{array}{c}\text { TABLE-4 } \\
\text { MEAN CONCENTRATIONS (ppm) OF Pb, Cd, As AND Hg IN CHINESE-ORIGIN BRANDS OF } \\
\text { FOUNDATION CREAMS COMMONLY USED IN THE KINGDOM OF SAUDI ARABIA }\end{array}$} & \\
\hline & \multicolumn{9}{|c|}{ Brands } \\
\hline & 1 & 2 & 3 & 4 & 5 & 6 & 7 & 8 & 9 \\
\hline $\mathrm{Pb}$ & 0.79 & 0.35 & 0.98 & 0.77 & 1.63 & 0.91 & 132.0 & 0.92 & 1.40 \\
\hline $\mathrm{Cd}$ & 0.04 & 0.04 & 0.07 & 0.05 & 0.10 & 0.05 & 0.09 & 0.07 & 0.06 \\
\hline As & 0.53 & 0.66 & 0.33 & 0.15 & - & - & 0 & 0.04 & - \\
\hline $\mathrm{Hg}$ & 0.03 & 0.03 & 0.01 & 0.01 & 0.02 & 0.02 & 0.04 & 0.02 & 0.01 \\
\hline
\end{tabular}


the concentrations of heavy metals among different brands, which explains theunevenness in their distribution in the examined samples.

Comparisons were also made to identify any relationship between the heavy metal concentrations and the colour of the foundation creams. The intensity of the colours was graded as dark, medium-dark, light and more-light. Arsenic and mercury concentrations did not show any relation with the color of the foundation creams. Cadmium and lead were absent in foundation creams with more-light colour, while they recorded their highest values in foundation creams with medium-dark to verydark colour, as shown in Table-5.

TABLE-5

CONCENTRATIONS (ppm) OF LEAD AND

CADMIUM IN SAMPLES BASED ON COLOR TONES

\begin{tabular}{ccccc}
\hline Element & Very-dark & $\begin{array}{c}\text { Medium- } \\
\text { dark }\end{array}$ & Light & More-light \\
\hline $\mathrm{Pb}$ & 0.89 & 0.72 & 0.10 & 0.00 \\
$\mathrm{Cd}$ & 0.09 & 0.06 & 0.06 & 0.00 \\
\hline
\end{tabular}

Cosmetics can be considered safe for use only if they adhere to international and local regulations and guidelines. Cosmetics contain a variety of ingredients that are challenging to digest, including fats and silica-based compounds. Microwave digestion with the addition of HF to digest siliceous materials may hence be necessary. Microwave digestion is also clean and retains mercury, so that a full suite of elements may be easily examined. As the results of this study indicate, ICP-OES is a good choice to determine analytes in low concentrations, allowing evaluation of the toxic and potentially toxic components in cosmetics.

\section{Conclusion}

In this study, most brands of foundation cream were found to be safe for use, as their heavy metal concentrations were within the permissible limits, except for some Chinese brands in which the lead content greatly exceeded the permissible limits. The frequent use of these brands may increase heavy metal levels in the human body, posing a serious risk to health. Hence, there should be stringent legislation to minimize or halt the import and marketing of brands that fail to follow international norms. Manufacturers should follow good manufacturing practices to minimize toxic impurities through quality testing of the finished products, according to international manufacturer specifications. Although the SFDA has started issuing specialized directives and guidelines to ensure the safety of cosmetic products, consumers can also play a crucial role in selecting and using only brands with good manufacturing practice certification. Further, consumers should be aware of the ingredients present in the products they are using and their effects. This study will aid in understanding and determining which brands violate international chemical regulations in the Kingdom of Saudi Arabia.

\section{ACKNOWLEDGEMENTS}

This work was supported by the Princess Nourahbint Abdulrahman University, Riyadh, Kingdom of Saudi Arabia.

\section{CONFLICT OF INTEREST}

The authors declare that there is no conflict of interests regarding the publication of this article.

\section{REFERENCES}

1. M. Bilal, T. Rasheed, J.E. Sosa-Hernandez, A. Raza, F. Nabeel and H.M.N. Iqbal, Mar. Drugs, 16, 65 (2018); https://doi.org/10.3390/md16020065.

2. J.A.M. Mahugija, Tanzan. J. Sci., 44, 1 (2018).

3. S. Gunther, G. Sven, S. Jorg, K. Waltraud and S. Uwe, Ullmann's Encyclopedia of Industrial Chemistry, Wiley VCH Verlag Gmbh and co, California, edn 5, pp. 201-220 (2002).

4. C. Juliano and G.A. Magrini, Cosmetics, 5, 19 (2018); https://doi.org/10.3390/cosmetics5010019.

5. O.G. Igharo, M.A. Okungbowa, E.L. Igharo and O.M. Ezegbogu, Niger. J. Pharm. Appl. Sci. Res., 7, 29 (2018).

6. European Union, EU Regulation (EC) No 1223/2009 of the European Parliament and of the Council of 30 November 2009 on Cosmetic Products, Official Journal L34259 (2009).

7. I. Felzenszwalb, A.D.S. Fernandes, L.B. Brito, G.A.R. Oliveira, P.A.S. Silva, M.E. Arcanjo, M.R.D.C. Marques, T. Vicari, D.M. Leme, M.M. Cestari and E.R.A. Ferraz, Environ. Sci. Pollut. Res. Int., (2018); https://doi.org/10.1007/s11356-018-1880-y.

8. J. Brandao, O. Okonkwo, M. Sehkula and R. Raseleka, Toxicol. Environ. Chem., 94, 70 (2012); https://doi.org/10.1080/02772248.2011.633911.

9. S. Balarastaghi, Z. Khashaiarmanesh, P. Makhdoumi, S.H. Alavizadeh, Z. Sameie Moghadam, K. Shirani and G. Karimi, Toxin Rev., 37, 117 (2018); https://doi.org/10.1080/15569543.2017.1328603.

10. US FDA, FDA's Testing of Cosmetics for Arsenic, Cadmium, Chromium, Cobalt, Lead, Mercury and Nickel Content. https://www.fda.gov/cosmetics/productsingredients/potential contaminants/ucm452836.

11. SFDA, Saudi Food and Drug Authority. http://sfda.gov.sa/en/cosmetic/pages/directives guidelines

12. SFDA, Saudi Food and Drug Authority, Cosmetic Products Safety Requirement, pp. 135 (2013).

13. D.S. Lim, T.H. Roh, M.K. Kim, Y.C. Kwon, S.M. Choi, S.J. Kwack, K.B. Kim, S. Yoon, H.S. Kim and B.M. Lee, J. Toxicol. Environ. Health A, 81, 432 (2018); https://doi.org/10.1080/15287394.2018.1451191.

14. S.S. Omenka and A.A. Adeyi, Toxicol. Rep., 3, 628 (2016); https://doi.org/10.1016/j.toxrep.2016.07.006.

15. F.B. Odukudu, J.G. Ayenimo, A.S. Adekunle, A.M. Yusuff and B.B. Mamba, Int. J. Consum. Stud., 38, 25 (2014); https://doi.org/10.1111/ijcs.12061.

16. M.M. Brzóska, M. Galazyn-Sidorczuk and S. Borowska, eds.: J.L. Chen and J.P. Thyssen, Metals in Cosmetics, In: Metal Allergy, Springer, pp. 177-196 (2018). https://doi.org/10.1007/978-3-319-58503-1 15.

17. A.K. Salama, Environ. Monit. Assess., 188, 553 (2016); https://doi.org/10.1007/s10661-016-5550-6.

18. M.G. Volpe, M. Nazzaro, R. Coppola, F. Rapuano and R.P. Aquino, Microchem. J., 101, 65 (2012); https://doi.org/10.1016/j.microc.2011.10.008.

19. K. Rehman, F. Fatima, I. Waheed and M.S.H. Akash, J. Cell. Biochem., 119, 157 (2018); https://doi.org/10.1002/jcb.26234.

20. Y.B. Ho, N.H. Abdullah, H. Hamsan and E.S.S. Tan, Regul. Toxicol. Pharmacol., 88, 72 (2017); https://doi.org/10.1016/j.yrtph.2017.05.018. 